\title{
Endotracheal Suctioning May or May Not Have an Impact, But It Does Depend on What You Measure!
}

Endotracheal suctioning is reportedly essential to maintain patency of an artificial airway in intubated and mechanically ventilated patients. However, the effectiveness of endotracheal suctioning alone to maintain airway patency is unclear. Endotracheal suctioning may also be associated with short-term physiological complications, such as lung de-recruitment and resultant hypoxemia in patients with acute lung injury. ${ }^{1}$ Factors that may determine the extent of lung de-recruitment or hypoxemia after endotracheal suctioning may include, but are not limited to, the method of suctioning (open or closed), the use of hyperoxygenation before/during the procedure, and the mode of mechanical ventilation (pressure or volume set). ${ }^{1,2}$ However, even with substantial lung volume loss during open suctioning, compared with closed suctioning, it may still be well tolerated and not result in any clinically important changes in arterial oxygenation or hemodynamics. ${ }^{2,3}$

In addition, the lung volume loss associated with closed suctioning may (counterintuitively) recover more slowly, compared to open suctioning. ${ }^{2}$ Therefore, it has been recommended that some form of lung recruitment be used after either open or closed suctioning, based on the extent of decrease in functional residual capacity after suctioning. ${ }^{4}$ What is becoming clear from the literature is that short-term changes in arterial oxygenation and hemodynamics, that may or may not be associated with endotracheal suctioning, may indicate changes in physiology (and not be related to patient outcome), but that measurements of efficacy of endotracheal suctioning are clearly lacking (artificial airway patency, airways resistance, mucus clearance).

The "blind" nature of advancing the suction catheter may be one of the major limitations to the procedure, and may lead to less efficient suctioning. ${ }^{5}$ This may in part explain the potential for adverse effects of endotracheal suctioning on lung function or risk of local trauma. For example, a closed suctioning procedure where the negative pressure is applied without any contact with mucus within the airway may have the potential for more deleterious effects on lung volume loss and may also push the secretions away from the suction catheter tip. ${ }^{6}$ When the suction catheter comes into direct contact with the mucus, this may be expected to have a less deleterious effect on lung volume and also be more efficacious in terms of secretion removal, especially without any PEEP. ${ }^{6}$ Hence, the development of optical fiber ports embedded within suction catheters ${ }^{5}$ and endotracheal tubes ${ }^{7}$ allows direct visualization during airway care to optimize secretion clearance, if the devices become commercially available ${ }^{5}$ and are also viable to use..$^{5,7}$

Recent recommendations for endotracheal suctioning8 advocate several key points to the procedure, including: to advance the suction catheter until resistance is met; to not apply suctioning routinely, but only as needed; to preferably use a closed suction catheter; to not use saline instillation; to pre-oxygenate; to use the shallow suctioning method; and to not apply suction pressure for more than 15 seconds. However, this clinical guidance ${ }^{8}$ seems not to be followed in clinical practice. ${ }^{9}$ The authors attribute this in part to the weak evidence to support some of the guidance. ${ }^{9}$

We may also ask ourselves why clinicians may or may not follow the American Association for Respiratory Care (AARC) guidance? Specific points of airway care in the AARC clinical practice guidelines ${ }^{8}$ merit further discussion. The AARC guidelines ${ }^{8}$ stipulate that endotracheal suctioning should be performed only when secretions are present, and not routinely (however, only followed by approximately $50 \%$ of clinicians ${ }^{9}$ ), and that shallow suctioning should be performed, as opposed to deep suctioning, for all intubated and mechanically ventilated patients (again, only followed by approximately $50 \%$ of clinicians ${ }^{9}$ ), which was based on neonatal literature. Deep suctioning is described as the insertion of a suction catheter until resistance is met, followed by withdrawal of the catheter by $1 \mathrm{~cm}$ before the application of negative pressure (there is no mention of the "stimulation" or assessment of a cough response to suctioning), and shallow suctioning as the insertion of a suction catheter to a pre-determined depth, usually the length of the artificial airway plus adapter. ${ }^{8,10}$

There is a preponderance of literature on airway suctioning and the various means to minimize the short-term physiological changes, such as arterial desaturation or changes in blood pressure and/or heart rate. ${ }^{1}$ However, these measures to minimize short-term physiological changes (such as arterial desaturation) may have the potential to also adversely impact on patient outcome(s). For example, if shallow suctioning were to become the stan- 
dard of care for all adult intubated and mechanically ventilated patients (as recommended by the AARC), the challenges for clinicians will be: the inability to assess the cough response to the suctioning procedure (hence suitability for extubation), especially in patients who are unable to follow commands; and the inability for clinicians to assess the true patency of the endotracheal tube. Biofilm and mucus accumulate on the inner lumen of the endotracheal tube with increasing time of intubation and mechanical ventilation. ${ }^{11}$ Standard endotracheal tube suctioning (on demand) and humidification do not prevent this build-up of mucus or biofilm. ${ }^{11}$ Endotracheal tube intraluminal volume loss due to mucus and biofilm buildup is also associated with an increased rate of ventilatorassociated pneumonia and longer mechanical ventilation. ${ }^{12}$ The degree of build-up of mucus and increase in airway resistance may be unpredictable, based on the duration of intubation, and hence may impact on weaning from ventilation. ${ }^{13,14}$

The Mucus Shaver, a device developed to remove inner lumen biofilm and mucus buildup, has been demonstrated to be more effective than standard suctioning and humidification. ${ }^{11}$ The concept of the Mucus Shaver, with a concentric inflatable catheter to remove secretions from the inner lumen of the endotracheal tube, ${ }^{11}$ provides insight into where standard endotracheal suctioning (greater than half the inner endotracheal tube lumen diameter) may have a capacity to maintain endotracheal tube patency. It is unclear which aspect of suctioning is actually responsible for the removal of secretions from the inner lumen of the endotracheal tube; for example, either the physical removal of secretions due to suction pressure, or due to the mechanical effect of the catheter on insertion/removal. ${ }^{15}$ If clearance of the inner lumen of the endotracheal tube is due to the mechanical or "pipe cleaner" effect of the suction catheter, then suctioning with a larger catheter may be more effective. ${ }^{15}$ Therefore, the recommendation of shallow suctioning as a standard of care, ${ }^{4}$ especially with closed suction methods, may be much less effective and may predispose the intubated and mechanically ventilated patient to increased risk of tube occlusion, may have the capacity to "blow" secretions away from the suction catheter (trigger inspiratory flow bias from ventilator breaths), unless the patient has a cough response (unlikely, as it is a shallow suctioning), and may in part explain why clinicians deviate from this clinical guidance. $6,9,15,16$

Open or closed suctioning, when combined with deep or shallow suctioning, ${ }^{8}$ may impact on treatment efficacy. For example, the shallow suctioning method may be more effective for secretion clearance when combined with open suctioning (ventilator circuit disconnection should result in an expiratory flow bias, due to the elastic recoil from passive expiration), as opposed to when combined with closed suctioning, where the negative pressure from the closed suction generated within the ventilator circuit may trigger ventilator breaths and generate an inspiratory flow bias (dependent on ventilator mode) and move or "blow" airway secretions away from the suction catheter tip. ${ }^{6}$

\section{SeE the Original Study on Page 1588}

In this issue of Respiratory CARe, Maggiore et al advocate the shallow suctioning method, ${ }^{17}$ as part of a package of airway care to reduce the short-term adverse effects of airway suctioning. However, the airway care recommendations proposed by Maggiore et al $^{17}$ require discussion. The potential for short-term adverse effects with endotracheal suctioning may include arterial oxygen desaturation, changes in blood pressure and heart rate, and local trauma to the airway. ${ }^{8}$ There is no evidence that links these short-term physiological changes with important patient outcomes such as mortality, mechanical ventilation duration, or ventilator-associated pneumonia, ${ }^{18}$ so there is no evidence to support either open or closed suctioning. Of note, the data collection period for the report from Maggiore et $\mathrm{al}^{17}$ was over a decade ago (between 2000 to 2001). The clinical relevance of these findings must be extrapolated on the basis of current practice. In the methods reported by Maggiore et al, ${ }^{17}$ these were based on evidence published ${ }^{16}$ after the trial had been conducted. Maggiore et $\mathrm{al}^{17}$ advocate that the shallow endotracheal suctioning method ${ }^{16}$ would be less deleterious, compared with standard or deep endotracheal suctioning. However, the shallow suctioning method described by Maggiore et al ${ }^{17}$ utilized closed suctioning (clinicians were to advance the suction catheter and insertion was stopped if an obstacle was met, and the suction catheter was withdrawn approximately $1 \mathrm{~cm}$. Suctioning was then started while gradually removing the catheter), as opposed to the open suctioning method originally used by Van de Leur et al. ${ }^{16}$ Shallow suctioning has been reported to be less effective for secretion clearance, compared with standard or deep suctioning. ${ }^{16}$ Van de Leur et al ${ }^{16}$ reported frequent trial violations in the group allocated to shallow suctioning (combined with open suction), where clinicians suspected the shallow suctioning method was ineffective (in terms of secretion removal) and the clinicians opted to use standard or deep suctioning.

The findings of Maggiore et al ${ }^{17}$ may indicate that the shallow suctioning method combined with closed suctioning may reduce the short-term adverse events (such as hypoxemia, hemodynamic changes, and mucosal trauma), but these short-term changes may be of questionable clinical importance. Maggiore et al ${ }^{17}$ demonstrated that, of the patients allocated to the shallow suctioning group, the trends in the data indicated that they required on average approximately 4 days more on mechanical ventilation $(P=.18)$, 
stayed in ICU for 6 more days $(P=.14)$ and had a trend toward more deaths $(51 \%$ vs $35 \%, P=.051)$, compared to the standard suctioning, which was not highlighted or discussed by the authors. Therefore, even though the standard suctioning ${ }^{17}$ may have been associated with more shortterm adverse effects (of unsubstantiated clinical relevance), it seems the standard suctioning procedure may also be associated with trends to better long-term patient outcomes; that requires more rigorous investigation. This may be due to reduced occlusion of the inner lumen of the endotracheal tube, with resultant potential benefits in terms of weaning and ventilator-associated pneumonia, but that requires investigation. The high mortality rate reported by Maggiore et al ${ }^{17}$ would not be expected of current general ICU admissions. Of note, Maggiore et a $1^{17}$ did not report on the ventilation requirements for the 2 different suctioning groups (eg, $\mathrm{F}_{\mathrm{IO}_{2}}$, PEEP, and mode of ventilation), so the findings of this trial require a more rigorous review.

In addition, as Maggiore et al ${ }^{17}$ instituted a multitude of changes combined with the shallow suctioning method (with over 9 separate components), it is difficult to interpret the true impact of this bundle of care. The other cofounding variable in this trial is the fact that the shallow suctioning method used by Maggiore et $\mathrm{al}^{17}$ was delivered with closed suctioning (or a variation with a suction port adaptor), with the patients nursed head-up, whereas in the original work by Van de Leur et al ${ }^{16}$ the shallow suctioning method was combined with open suctioning and with supine patient position (a modified form of postural drainage), which may be more efficacious, due to the effects of gravity, and with the potential to create an expiratory flow bias, due to lung elastic recoil during the passive expiration with circuit disconnection. Maggiore et al ${ }^{17}$ only reported on arterial oxygenation and hemodynamics, whereas the need for additional chest physiotherapy, manual lung ventilation, endotracheal tube changes, and therapeutic bronchoscopy for severe hypoxemic or mucus occlusion events may have provided greater insight into the potential for airway occlusion events. ${ }^{19}$

The use of saline instillation with airway suctioning is not recommended. ${ }^{8}$ However, the increased clearance of wet weight of secretions ${ }^{20}$ and a reduced rate of ventilatorassociated pneumonia ${ }^{21}$ are associated with the use of saline instillation. The exact mechanisms behind these outcomes are not yet understood; however, the dislodgement of bio-

\footnotetext{
The author has disclosed no conflicts of interest.

Correspondence: George Ntoumenopoulos PhD Grad Dip Clin Epid, School of Physiotherapy, Australian Catholic University, Level 2, 173 Pacific Highway, North Sydney 2060, Australia. E-mail: georgentou@yahoo.com.
}

DOI: $10.4187 /$ respcare. 02745 film with reduction of the bacterial burden and subsequent clearance of secretions with saline instillation, cough, and suctioning have been proposed as to the reasoning behind the significant reduction in ventilator-associated pneumonia. ${ }^{21}$ The question of the appropriate outcome tools to determine the impact of and need for interventions such as airway suctioning, or even the use of saline instillation, is unclear. ${ }^{22}$ The impact of airway secretion clearance on measures such as flow waveform pattern, airways resistance, and physiological dead space $22-24$ may be more appropriate measures of efficacy, rather than a focus on shortterm changes in arterial saturation, blood pressure, or heart rate.

We must distinguish between the potential for shortterm changes in physiology of unknown clinical relevance ${ }^{18}$ and the potential for improvements in lung mechanics that may be of more relevance, but that requires further investigation. It is known that intubation and mechanical ventilation do cause buildup of mucus and biofilm on the endotracheal airway, but the outcome tools to detect these changes may not be applicable at the bedside. ${ }^{12} \mathrm{We}$ must further investigate the bedside tools to detect secretion retention, ${ }^{22,25,26}$ monitor the impact of secretion retention on patient outcome, and then investigate the various therapeutic strategies available to optimize secretion clearance (and endotracheal tube airway patency). The current guidance on endotracheal suctioning ${ }^{8}$ may need to be investigated in terms of the optimal methods to detect and maintain endotracheal tube patency, which may then advocate the use of strategies currently deemed to be controversial, such as larger than normal endotracheal suction catheters, saline instillation, and open suctioning.

\section{George Ntoumenopoulos PhD Grad Dip Clin Epid}

School of Physiotherapy

Australian Catholic University

North Sydney, Australia

\section{REFERENCES}

1. Maggiore SM, Lellouche F, Pigeot J, Taillé S, Deye N, Durrmeyer $\mathrm{X}$, et al. Prevention of endotracheal suctioning-induced alveolar derecruitment in acute lung injury. Am J Respir Crit Care Med 2003; 167(9):1215-1224.

2. Corley A, Spooner AJ, Barnett AG, Caruana LR, Hammond NE, Fraser JF. End-expiratory lung volume recovers more slowly after closed endotracheal suctioning than after open suctioning: a randomized crossover study. J Crit Care 2012;27(6):742, e741-e747.

3. Jongerden IP, Kesecioglu J, Speelberg B, Buiting AG, Leversteinvan Hall MA, Bonten MJ. Changes in heart rate, mean arterial pressure, and oxygen saturation after open and closed endotracheal suctioning: a prospective observational study. J Crit Care 2012;27(6): 647-654.

4. Heinze H, Eichler W, Karsten J, Sedemund-Adib B, Heringlake M, Meier T. Functional residual capacity-guided alveolar recruitment 


\section{Endotracheal Suctioning May or May Not Have an Impact}

strategy after endotracheal suctioning in cardiac surgery patients. Crit Care Med 2011;39(5):1042-1049.

5. Lv J, Wu J, Guo R, Liu X, Yan B, Deng H. Laboratory test of a visual sputum suctioning system. Respir Care 2013;58(10):1637-1642.

6. Lindgren S, Almgren B, Hogman M, Lethvall S, Houltz E, Lundin S, et al. Effectiveness and side effects of closed and open suctioning: an experimental evaluation. Intensive Care Med 2004;30(8):1630-1637.

7. Barak M, Putilov V, Meretyk S, Halachmi S. ETView tracheoscopic ventilation tube for surveillance after tube position in patients undergoing percutaneous nephrolithotomy. Br J Anaesth 2010;104(4): 501-504.

8. American Association for Respiratory Care. Clinical Practice Guidelines. Endotracheal suctioning of mechanically ventilated patients with artificial airways 2010. Respir Care 2010;55(6):758-764.

9. Beuret P, Roux C, Constan A, Mercat A, Brochard L. Discrepancy between guidelines and practice of tracheal suctioning in mechanically ventilated patients: a French multicenter observational study. Intensive Care Med 2013;39(7):1335-1336.

10. Clifton-Koeppel R. Endotracheal tube suctioning in the newborn: a review of the literature. Newborn Infant Nurs Rev 2006;6(2):94-99.

11. Berra L, Coppadoro A, Bittner EA, Kolobow T, Laquerriere P, Pohlmann JR, et al. A clinical assessment of the Mucus Shaver: a device to keep the endotracheal tube free from secretions. Crit Care Med 2012;40(1):119-124.

12. Shah C, Kollef MH. Endotracheal tube intraluminal volume loss among mechanically ventilated patients. Crit Care Med 2004;32(1): 120-125.

13. Wilson A, Gray D, Karakiozis J, Thomas J. Advanced endotracheal tube biofilm stage, not duration of intubation, is related to pneumonia. J Trauma Acute Care Surg 2012;72(4):916-923.

14. Wilson AM, Gray DM, Thomas JG. Increases in endotracheal tube resistance are unpredictable relative to duration of intubation. Chest 2009;136(4):1006-1013.

15. Morrow BM, Futter MJ, Argent AC. Endotracheal suctioning: from principles to practice. Intensive Care Med 2004;30(6):11671174 .

16. Van de Leur JP, Zwaveling JH, Loef BG, Van der Schans CP. Endotracheal suctioning versus minimally invasive airway suction- ing in intubated patients: a prospective randomised controlled trial. Intensive Care Med 2003;29(3):426-432.

17. Maggiore SM, Lellouche F, Pignataro C, Girou E, Maitre B, Richard JC, et al. Decreasing the adverse effects of endotracheal suctioning during mechanical ventilation by changing practice. Respir Care 2013;58(10):1588-1597.

18. Jongerden IP, Rovers MM, Grypdonck MH, Bonten MJ. Open and closed endotracheal suction systems in mechanically ventilated intensive care patients: a meta-analysis. Crit Care Med 2007;35(1): 260-270.

19. Templeton M, Palazzo MG. Chest physiotherapy prolongs duration of ventilation in the critically ill ventilated for more than 48 hours. Intensive Care Med 2007;33(11):1938-1945.

20. Giakoumidakis K, Kostaki Z, Patelarou E, Baltopoulos G, Brokalaki $\mathrm{H}$. Oxygen saturation and secretion weight after endotracheal suctioning. Br J Nurs 2011;20(21):1344-1351.

21. Caruso P, Denari S, Ruiz SA, Demarzo SE, Deheinzelin D. Saline instillation before tracheal suctioning decreases the incidence of ventilator-associated pneumonia. Crit Care Med 2009;37(1):3238.

22. Guglielminotti J, Alzieu M, Maury E, Guidet B, Offenstadt G. Bedside detection of retained tracheobronchial secretions in patients receiving mechanical ventilation: is it time for tracheal suctioning? Chest 2000;118(4):1095-1099.

23. Main E, Castle R, Newham D, Stocks J. Respiratory physiotherapy vs suction: the effects on respiratory function in ventilated infants and children. Intensive Care Med 2004;30(6):1144-1151.

24. Main E, Stocks J. The influence of physiotherapy and suction on respiratory deadspace in ventilated children. Intensive Care Med 2004;30(6):1152-1159.

25. Ntoumenopoulos G, Glickman Y. Computerised lung sound monitoring to assess effectiveness of chest physiotherapy and secretion removal: a feasibility study. Physiotherapy 2012;98(3):250-255.

26. Lucchini A, Zanella A, Bellani G, Gariboldi R, Foti G, Pesenti A, et al. Tracheal secretion management in the mechanically ventilated patient: comparison of standard assessment and an acoustic secretion detector. Respir Care 2011;56(5):596-603. 